\title{
Long-term response to Crizotinib in a 17-year-old boy with naive alk-positive Non-Small Cell Lung Cancer
}

\author{
giacomina megaro ${ }^{1}$, Evelina Miele ${ }^{2}$, Gian Paolo Spinelli ${ }^{3}$, Iside Alessi ${ }^{4}$, Giada Del Baldo ${ }^{4}$, \\ Raffaele Cozza ${ }^{4}$, Ida Russo ${ }^{2}$, Maria Debora De Pasquale ${ }^{4}$, Maria Giuseppina Cefalo ${ }^{4}$, Paolo \\ Toma $^{5}$, Valentina Di Ruscio ${ }^{6}$, Maria Antonietta De Ioris ${ }^{1}$, and Angela Mastronuzzi ${ }^{4}$ \\ ${ }^{1}$ Ospedale Pediatrico Bambino Gesù \\ ${ }^{2}$ Ospedale Pediatrico Bambino Gesu \\ ${ }^{3}$ UOC Oncologia Universitaria, ASL Latina (distretto Aprilia), Sapienza University of \\ Rome \\ ${ }^{4}$ Bambino Gesu Pediatric Hospital \\ ${ }^{5}$ Bambino Gesù Children's Research Hospitals \\ ${ }^{6}$ Bambino Gesù Pediatric Hospital
}

November 24, 2020

\begin{abstract}
Lung cancer is the leading cause of cancer-related death. NSCLC accounts for $80-90 \%$ of cases. In younger patients, adenocarcinoma is the most frequent histotype and 3-7\% expresses the rearrange-ment of ALK oncogene, sensitive to TKIs. Crizotinib is the first ALK inhibitor approved by FDA. We present the case of a 17-year-old male with metastatic naïve ALK-positive adenocarcinoma, treated with crizotinib. He received crizotinib and obtained a prolonged response with PFS of 33 months. Crizotinib can be extremely effective in adolescent with naïve ALK-positive NSCLC but it hardly penetrates blood-brain barrier. Resistance mechanisms will be investigated for a better man-agement.
\end{abstract}

\section{LONG-TERM RESPONSE TO CRIZOTINIB IN A 17-YEAR-OLD BOY WITH NAÏVE ALK-POSITIVE NON-SMALL-CELL LUNG CANCER}

Megaro Giacomina ${ }^{1 *}$, Miele Evelina ${ }^{1}$, Spinelli Gian Paolo ${ }^{2}$, Alessi Iside ${ }^{1}$, Del Baldo Giada ${ }^{1}$, Cozza Raffaele $^{1}$, Russo Ida ${ }^{1}$, De Pasquale Maria Debora ${ }^{1}$, Cefalo Maria Giuseppina ${ }^{1}$, Tomà Paolo ${ }^{3}$, Di Ruscio Valentina ${ }^{1}$, De Ioris, Maria Antonietta ${ }^{1}$, Mastronuzzi Angela ${ }^{1}$

${ }^{1}$ Department of Hematology/Oncology, Cell and Gene Therapy, IRCCS Bambino Gesù Children's Hospital, Rome, Italy

${ }^{2}$ UOC Oncologia Universitaria, ASL Latina (distretto Aprilia), Sapienza University of Rome- Aprilia, Latina, Italy.

3 Department of Imaging, Bambino Gesù Children's Hospital, IRCCS, Rome, Italy.

* Corresponding author: Giacomina Megaro, Piazza di Sant'Onofrio 4, Rome, 00165, Italy,giacomina.megaro@opbg.net; Tel.: 00393884699597;

Abstract: 99 words

Main text: 1127 words 


\section{Tables: 1}

Figures: 1

Keywords: lung, adenocarcinoma, ALK, adolescence, crizotinib

\begin{tabular}{ll}
\hline Abbreviation & Full term \\
\hline SCLS & Small Cell Lung Cancer \\
NSCLC & Non-Small Cell Lung Cancer \\
EGFR & Epidermal Growth Factor Receptor \\
ALK & Anaplastic Lymphoma Kinase \\
TKI & Tyrosine Kinase Inhibitor \\
EML-4 & Echinoderm Microtubule-associated Protein Like-4 \\
FDA & Food and Drug Administration \\
PFS & Progression-Free Survival \\
CT & Computed Tomography \\
MRI & Magnetic Resonance Imaging \\
CK7+ & Cytokeratine 7+ \\
TTF1+ & Transcriptional Thyroid Factor 1+ \\
ROS1 & c-Ros Oncogene 1 \\
CTCAE & Common Terminology Criteria for Adverse Events \\
CNS & Central Nervous System \\
BBB & Blood-Brain Barrier \\
\hline
\end{tabular}

\section{Hosted file}

Long term response to crizotinib.pdf available at https://authorea.com/users/378293/articles/ 494822-long-term-response-to-crizotinib-in-a-17-year-old-boy-with-naive-alk-positivenon-small-cell-lung-cancer

\section{Hosted file}

table.pdf available at https://authorea.com/users/378293/articles/494822-long-term-responseto-crizotinib-in-a-17-year-old-boy-with-naive-alk-positive-non-small-cell-lung-cancer

\section{Hosted file}

figures.pdf available at https://authorea.com/users/378293/articles/494822-long-termresponse-to-crizotinib-in-a-17-year-old-boy-with-naive-alk-positive-non-small-celllung-cancer 